Article

\title{
New Potential Antimalarial Agents: Design, Synthesis and Biological Evaluation of Some Novel Quinoline Derivatives as Antimalarial Agents
}

\author{
Ibrahim Ali M. Radini ${ }^{1}$, Tarek M. Y. Elsheikh ${ }^{2,3}$, Emad M. El-Telbani ${ }^{1,4}$ and Rizk E. Khidre ${ }^{1,4, *}$ \\ 1 Chemistry Department, Faculty of Science, Jazan University, Jazan 2097, Saudi Arabia; \\ iradini4@gmail.com (I.A.M.R.); dremade1966@yahoo.co.uk (E.M.E.-T.) \\ 2 Biology Department, Faculty of Science, Jazan University, Jazan 2097, Saudi Arabia; \\ telsheikh1964@yahoo.com \\ 3 Department of Zoology, Faculty of Science, Al-Azhar University, Cairo 11675, Egypt \\ 4 Chemical Industries Division, National Research Centre, Dokki 12622, Giza, Egypt \\ * Correspondence: rizkkhidre@yahoo.com; Tel.: +966-59-298-0669
}

Academic Editors: Wei-Zhu Zhong and Shufeng Zhou

Received: 26 May 2016; Accepted: 8 July 2016; Published: 14 July 2016

\begin{abstract}
A novel series of dihydropyrimidines (DHPMs) 4a-j; 2-oxopyran-3-carboxylate 7a,b; 1-amino-1,2-dihydropyridine-3-carboxylate 8; and 1,3,4-oxadiazole derivatives 12 with quinolinyl residues have been synthesized in fairly good yields. The structure of the newly synthesized compounds was elucidated on the basis of analytical and spectral analyses. In vitro antimalarial evaluation of the synthesized quinoline derivatives against Plasmodium falciparum revealed them to possess moderate to high antimalarial activities, with $\mathrm{IC}_{50}$ values ranging from $0.014-5.87 \mu \mathrm{g} / \mathrm{mL}$. Compounds $\mathbf{4 b}, \mathbf{g}, \mathbf{i}$ and $\mathbf{1 2}$ showed excellent antimalarial activity against to Plasmodium falciparum compared with the antimalarial agent chloroquine (CQ).
\end{abstract}

Keywords: quinoline-4-carbaldehyde; Biginelli reaction; dihydropyrimidines; antimalarial activities; Plasmodium falciparum

\section{Introduction}

Malaria is one of the principal diseases of the developing countries, particularly in Africa, Asia and South America. According to a World Health Organization (WHO) report, there are between 300 million and 500 million cases of malaria worldwide annually and more than one million people die from that disease, most of them are children under the age of five years [1,2]. Among five typically recognized Plasmodium species causing this disease in humans, Plasmodium falciparum is responsible for about $95 \%$ of worldwide malaria and has a mortality rate of $1 \%-3 \%$, and Plasmodium vivax for most morbidity, additionally representing a reservoir of latent infection that hampers current control and future elimination efforts [3-6]. Due to the toxic side effects and the risk of developing resistance after prolonged treatment with aminoquinolines and their derivatives (Figure 1) which are nowadays used as antimalarial agents, the growth of and increasing resistance $[7,8]$ of the malaria parasite Plasmodium falciparum to known antimalarial agents demands a continuous effort to develop new antimalarial agents especially, as an effective vaccine for malaria is not available. 
<smiles>Nc1ccnc2ccccc12</smiles>

4-Aminoquinoline<smiles>CCN(CC)CCCC(C)Nc1ccnc2cc(Cl)ccc12</smiles><smiles>CCN(CC)Cc1cc(Nc2ccnc3cc(Cl)ccc23)ccc1O</smiles><smiles>CCN(CCO)CCCC(C)Nc1ccnc2cc(Cl)ccc12</smiles>

Hydroxychloroquine

Figure 1. Aminoquinoline and their derivatives as antimalarial agents.

In addition, quinoline-based fused heterocyclic systems are found to possess potential antimicrobial [9,10], antimalarial [11,12], anti-inflammatory [13,14], antitumor [15], and anti-parasitic activity [16].

Currently there are only limited safe drugs for the treatment of the disease, however, the design of new chemical agents, specifically affecting these targets, could lead to the availability of better drugs to treat malaria. Based on the above information and in continuation with our previous work $[11,15,17,18]$, quinoline-based antimalarials that would not induce resistance, we have designed and prepared several quinolines compounds and screened for their antimalarial activities. Hopefully, these compounds will be active on the CQ-resistant strain FcB1 and could lead to the availability of better drugs to treat malaria.

\section{Results}

\subsection{Chemistry}

Dihydropyrimidin-2(1H)-ones (DHPMs) and their derivatives have received much attention because they are important substructures in both biologically active compounds and several marine alkaloids involving DHPM core units [19-21]. A facile three-component Biginelli's one-pot cyclo-condensation reaction takes place between the quinolinealdehydes namely, tetrazolo-[1,5-a]quinoline-4-carbaldehyde (1a), 7-methyltetrazolo[1,5-a]quinoline-4-carbaldehyde (1b) [22,23], 2-oxo-1,2-dihydroquinoline-3-carbaldehyde (1c) [24]; ethyl acetoacetate (2a) or acetylacetone (2b); and (thio)urea 3 in ethanol in the presence of a catalytic amount of hydrochloric acid at reflux temperature to yield dihydropyrimidine (DHPMs) $4 \mathbf{a}-\mathbf{j}$ in good yield [25,26] (Scheme 1 and Experimental Section).

The structure of products $\mathbf{4} \mathbf{a}-\mathbf{j}$ has been confirmed by both analytical and spectral analyses. The presence of a single proton at a range of $\delta=5.41-5.91$ ppm corresponding to H-4 of DHPMs in addition to the two NH groups at $\delta=7.13-9.24$ ppm and 9.29-11.79 ppm supported the suggested DHPMs structures. Also, molecular weight determination $\left(\mathrm{M}_{\mathrm{S}}\right)$ confirmed their structures. (cf. Scheme 1 and Experimental Section).

The synthetic strategies adopted to obtain the target $\mathbf{8}$ and $\mathbf{1 2}$ are somewhat long and linear with few common intermediates. To this aim, the chalcones derivatives $\mathbf{6} \mathbf{a}, \mathbf{b}$, which were prepared by reaction of 2-(piperidin-1-yl)quinoline-3-carbaldehyde (1d) [27] with methyl ketones 5a,b, were reacted with ethyl cyanoacetate in ethanol at room temperature to give pyran-3-carboxylate derivatives $7 \mathbf{a}, \mathbf{b}$ in fairly good yield (Scheme 2). The structures of compounds 7 were established by both analytical and spectral analyses. The IR spectra show two absorption bands at $1690-1682 \mathrm{~cm}^{-1}$ and $1743-1736 \mathrm{~cm}^{-1}$ for the ester and lactone carbonyl groups, respectively. In addition, the ${ }^{1} \mathrm{H}-\mathrm{NMR}$ shows the pyran $\mathrm{H}-5$ at $\delta 7.33-7.39 \mathrm{ppm}$ and other protons in their expected locations. $N$-Nucleophilic addition reaction 
of hydrazine at the lactonic carbonyl group of 7a, gave 1,2-dihydropyridine-3-carboxylate derivative 8. The IR spectra showed absence of the lactonic carbonyl group perilously appeared in the parent 7 and the appearance of new bands at $v 3383,3182 \mathrm{~cm}^{-1}$ due to $\mathrm{NH}_{2}$ function and ${ }^{1} \mathrm{H}-\mathrm{NMR}$ showed a singlet signal at $\delta 5.41 \mathrm{ppm}$ attributed to amino group.<smiles>[R7]C([15NH2])[18F]</smiles>

1a-c<smiles>[R]C(=O)CC(C)=O</smiles>

2<smiles>[X]C(N)=C1CCCCC1(C)O</smiles>

3<smiles>[R]C(=O)C1=C(C)NC([X])=NC1[R]</smiles>

4a-j

Compound

Scheme 1. Synthesis of dihydropyridine (DHPMs) $4 \mathbf{a}-\mathbf{j}$.<smiles>O=Cc1cc2ccccc2nc1N1CCCCC1</smiles><smiles>[R3]C(=O)[18O]</smiles>

$\mathrm{EtOH}, \mathrm{NaOH}$ $1 d$<smiles>O=C(F)/C=C/c1cc2ccccc2nc1N1CCCCC1</smiles>

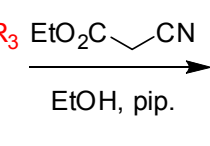

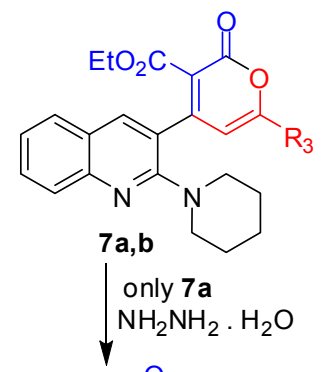<smiles>CCOC(=O)c1nc2ccccc2cc1-c1cc(-c2ccccc2)n(N)c(=O)c1C(C)C</smiles>

Scheme 2. Synthesis of quinolinyl 1,2-dihydropyridine 8.

2-Chloroquinoline-3-carboxylic acid was prepared by oxidation of 1e using silver nitrate in the presence of sodium hydroxide [28]. Esterification of the carboxylic acid derivative 9 using 
absolute ethanol and sulfuric acid afforded the ester derivative 10, in a good yield, followed by subsequent hydrazinolysis in boiling ethanol to afford 2-chloroquinoline-3-carbohydrazide 11. The later compound $\mathbf{1 1}$ was subjected to react with carbon disulfide in ethanol in the presence of $\mathrm{KOH}$ under reflux followed by acidification by using diluted hydrochloric acid to give 5-(2-chloro-quinolin-3-yl)-1,3,4-oxadiazole-2-thiol (12). The IR spectrum showed the presence of the absorption band at $2500 \mathrm{~cm}^{-1}$ due to S-H function, in addition ${ }^{13} \mathrm{C}-\mathrm{NMR}$ revealed signal at $\delta_{\mathrm{C}} 164.54$ (C2-1,3,4-oxadiazole) ppm indicates that 12 exists in the thiol form (cf. Scheme 3 and Experimental Section).

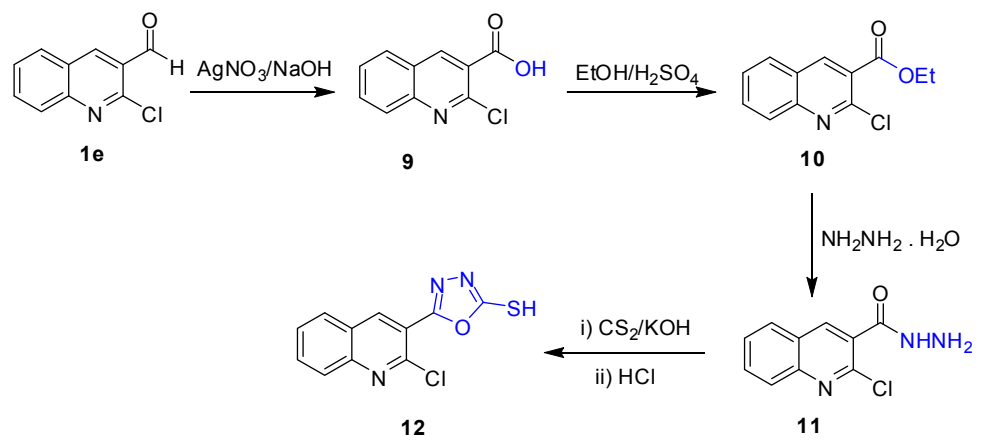

Scheme 3. Synthesis of quinoliny 1,3,4-oxadiazole 12.

\subsection{Antimalarial Evaluation}

Seventeen quinoline derivatives were evaluated in vitro against $P$. falciparum. The results of the antimalarial screening are presented in Tables 1-3. The basic measurement of antimalarial activity used in this study was the reduction in number of parasitized cells in the test cultures compared to control at 36-48 h of incubation. Compounds exhibiting IC $_{50} P$. falciparum $>5 \mu \mathrm{g} / \mathrm{mL}$ was considered inactive. If the $\mathrm{IC}_{50}$ is between 0.5 and $5 \mu \mathrm{g} / \mathrm{mL}$, the compound is classified as moderately active. If the $\mathrm{IC}_{50}$ is $<0.5 \mu \mathrm{g} / \mathrm{mL}$, the compound is classified as active.

Table 1. \% Parasite inhibition of Plasmodium falciparum by some quinolinyl derivatives 4-12.

\begin{tabular}{|c|c|c|c|c|c|c|c|c|}
\hline \multirow{3}{*}{ Compound } & \multicolumn{8}{|c|}{ \% Mean Parasite Inhibition Per 1500 RBC } \\
\hline & \multicolumn{2}{|c|}{0.625} & \multicolumn{2}{|c|}{1.25} & \multicolumn{2}{|c|}{2.5} & \multicolumn{2}{|r|}{5} \\
\hline & Range & Mean $\pm S E$ & Range & Mean $\pm S E$ & Range & Mean $\pm S E$ & Range & Mean \pm SE \\
\hline $4 a$ & $2.0-7.8$ & $5.7 \pm 1.85$ & $8.2-18.2$ & $14.1 \pm 3.02$ & $31.3-41.8$ & $36.6 \pm 3.03$ & $47.1-53.1$ & $51.0 \pm 1.93$ \\
\hline $4 e$ & $0.0-2.0$ & $1.3 \pm 0.63$ & $2.0-7.2$ & $4.4 \pm 1.51$ & $13.7-14.2$ & $14.1 \pm 0.23$ & $24.4-35.2$ & $29.5 \pm 3.12$ \\
\hline $4 f$ & $9.8-12.2$ & $10.9 \pm 0.69$ & $27.4-29.1$ & $28.3 \pm 0.49$ & $32.7-43.1$ & $37.5 \pm 3.02$ & $69.1-78.4$ & $72.9 \pm 2.79$ \\
\hline $4 h$ & $20.4-23.6$ & $21.8 \pm 0.93$ & $24.5-35.2$ & $31.4 \pm 3.05$ & $69.1-75.5$ & $72.3 \pm 1.84$ & $80-83.7$ & $82.0 \pm 1.07$ \\
\hline $4 \mathbf{j}$ & 1.9-7.2 & $3.7 \pm 1.75$ & $0.0-5.4$ & $2.5 \pm 1.57$ & 19.6-20.4 & $20.0 \pm 0.23$ & $49-56.8$ & $51.6 \pm 2.58$ \\
\hline $6 b$ & $42.8-43.6$ & $43.2 \pm 0.23$ & $52.7-62.7$ & $56.2 \pm 3.26$ & $55.1-69.1$ & $61.0 \pm 4.18$ & 100-100 & $100 \pm 00$ \\
\hline 11 & 5.9-18.2 & $12.8 \pm 3.62$ & $39.2-49$ & $44.6 \pm 2.86$ & $63.2-74.5$ & $70.1 \pm 350$ & $75.5-83.6$ & $80.0 \pm 2.51$ \\
\hline 12 & $35.3-45.4$ & $41.8 \pm 3.27$ & $59.2-70.9$ & $64.3 \pm 3.46$ & $74.5-78.2$ & $76.7 \pm 1.13$ & $86.3-91.8$ & $89.7 \pm 1.70$ \\
\hline $\mathrm{CQ}$ & $59.9-63.8$ & $61.8 \pm 1.13$ & 75.9-78.1 & $76.7 \pm 0.67$ & 100-100 & $100 \pm 0.0$ & - & - \\
\hline
\end{tabular}


Table 2. \% Parasite inhibition of Plasmodium falciparum (\% Mean Parasite Inhibition per 1500 RBC) of compounds $4 \mathbf{b}, \mathbf{g}, \mathbf{i}$.

\begin{tabular}{|c|c|c|c|c|c|}
\hline \multirow{2}{*}{\multicolumn{2}{|c|}{ Concentrations $(\mu \mathrm{g} / \mathrm{mL})$}} & \multicolumn{4}{|c|}{ Compound } \\
\hline & & \multirow{3}{*}{$\begin{array}{c}\mathbf{4 b} \\
\mathrm{NP} \\
\mathrm{NP}\end{array}$} & \multirow{3}{*}{$\begin{array}{l}\mathbf{4 g} \\
\mathrm{NP} \\
\mathrm{NP}\end{array}$} & \multirow{3}{*}{$\begin{array}{c}\mathbf{4 i} \\
32.7-36.7 \\
34.8 \pm 1.16\end{array}$} & \multirow{3}{*}{$\begin{array}{l}\text { CQ } \\
\mathrm{NP} \\
\mathrm{NP}\end{array}$} \\
\hline & Range & & & & \\
\hline 0.078 & Mean \pm SE & & & & \\
\hline \multirow{2}{*}{0.156} & Range & NP & $23.5-25.4$ & NP & $28.9-33.7$ \\
\hline & Mean \pm SE & NP & $24.4 \pm 0.54$ & NP & $31.8 \pm 1.44$ \\
\hline \multirow{2}{*}{0.312} & Range & $41.8-44.9$ & $56.3-61.2$ & $63.6-71.4$ & $43.3-46.4$ \\
\hline & Mean \pm SE & $43.3 \pm 0.89$ & $58.7 \pm 1.41$ & $67.8 \pm 2.28$ & $44.9 \pm 0.90$ \\
\hline \multirow{2}{*}{0.625} & Range & $55.1-70.1$ & $82.3-89.7$ & $74.5-86.2$ & $59.9-63.8$ \\
\hline & Mean \pm SE & $63.3 \pm 4.38$ & $87.0 \pm 2.35$ & $79.4 \pm 3.5$ & $61.8 \pm 1.13$ \\
\hline \multirow{2}{*}{1.25} & Range & $73.5-82.3$ & $100-100$ & $85.7-94.1$ & $75.9-78.1$ \\
\hline & Mean \pm SE & $76.7 \pm 2.78$ & $100 \pm 0.0$ & $89.9 \pm 2.59$ & $76.7 \pm 0.67$ \\
\hline \multirow{2}{*}{2.5} & Range & $89.1-95.9$ & - & $100-100$ & $100-100$ \\
\hline & Mean \pm SE & $91.7 \pm 2.11$ & - & $100 \pm 0.0$ & $100 \pm 0.0$ \\
\hline \multirow{2}{*}{5} & Range & $100-100$ & - & - & - \\
\hline & Mean \pm SE & $100 \pm 0.0$ & - & - & - \\
\hline
\end{tabular}

Table 3. $\mathrm{IC}_{50}$ values of some derivatives compound of chloroquine against Plasmodium falciparum.

\begin{tabular}{cccc}
\hline Compound & $\mathbf{I C}_{\mathbf{5 0}}(\boldsymbol{\mu} \mathbf{g} / \mathbf{m L})$ & Slope & $\mathbf{R}^{\mathbf{2}}$ \\
\hline $\mathbf{4 a}$ & 4.59 & 10.32 & 0.929 \\
$\mathbf{4} \mathbf{b}$ & 0.46 & 10.43 & 0.772 \\
$\mathbf{4 c}$ & 2.39 & 16.28 & 0.968 \\
$\mathbf{4 d}$ & 15.87 & 3.17 & 0.932 \\
$\mathbf{4} \mathbf{e}$ & 8.10 & 6.55 & 0.997 \\
$\mathbf{4} \mathbf{f}$ & 3.29 & 13.34 & 0.977 \\
$\mathbf{4 g}$ & 0.30 & 61.62 & 0.791 \\
$\mathbf{4 h}$ & 2.21 & 14.0 & 0.831 \\
$\mathbf{4} \mathbf{i}$ & 0.014 & 23.48 & 0.733 \\
$\mathbf{4} \mathbf{j}$ & 4.96 & 11.67 & 0.975 \\
$\mathbf{6 a}$ & 1.13 & 12.41 & 0.965 \\
$\mathbf{7 a}$ & 2.09 & 9.11 & 0.790 \\
$\mathbf{7} \mathbf{b}$ & 1.06 & 14.14 & 0.889 \\
$\mathbf{8}$ & 0.76 & 29.79 & 0.971 \\
$\mathbf{1 0}$ & 1.91 & 13.27 & 0.782 \\
$\mathbf{1 1}$ & 2.21 & 13.59 & 0.767 \\
$\mathbf{1 2}$ & 0.46 & 9.62 & 0.834 \\
$\mathbf{C Q}$ & 0.49 & 27.01 & 0.927 \\
\hline
\end{tabular}

The percentages of inhibition plasmodial parasite were recorded in Tables $1-3$. The data revealed that the highest percent of inhibition (100\%) was recorded by $\mathbf{4 b}, \mathbf{4} \mathbf{g}, \mathbf{4} \mathbf{i}, \mathbf{6 a}, \mathbf{7 b}$ and $8 \mathbf{b}$ at the concentrations 5.0, 1.25, 2.50, 5.0, 5.0, and $2.50 \mu \mathrm{g} / \mathrm{mL}$, respectively. Also, 4b, 4c, 4g-i, 8a, 10, 11 and 12 showed inhibition more than $75 \%$ of plasmodial parasite at the concentrations 1.25, 5.0, 0.625, $5.0,0.625,2.50,5.0,5.0$ and $2.50 \mu \mathrm{g} / \mathrm{mL}$, respectively. At the lowest concentrations $0.312,0.156$ and $0.078 \mu \mathrm{g} / \mathrm{mL}, \mathbf{4 b}, \mathbf{4} \mathbf{g}, \mathbf{4} \mathbf{i}$ showed significant effect against parasite where the inhibition percentage were $43.3 \% \pm 0.89 \%, 24.4 \% \pm 0.54 \%$, and $34.8 \% \pm 1.16 \%$.

Median inhibitory concentrations $\left(\mathrm{IC}_{50}\right)$ of synthesized compounds against $P$. falciparum in vitro are summarized in Table 3. The $\mathrm{IC}_{50}$ values for these compounds were in the range $0.014-15.87 \mu \mathrm{g} / \mathrm{mL}$. Two compounds exhibited $\mathrm{IC}_{50}$ values more than $5 \mu \mathrm{g} / \mathrm{mL}$ against $P$. falciparum. Twelve compounds (4a, 4c, 4f, 4h, 4j, 6a, 7a,b, 8a,b, 10, 11) showed $\mathrm{IC}_{50}$ values between $0.5 \mu \mathrm{g} / \mathrm{mL}$ and $5 \mu \mathrm{g} / \mathrm{mL}$, and 
considered a moderately active. Four compounds $(\mathbf{4 b}, \mathbf{4} \mathbf{j}, \mathbf{4 i}$ and $\mathbf{1 2})$ were classified as active with $\mathrm{IC}_{50}$ $(0.46,0.30,0.014$ and $0.46 \mu \mathrm{g} / \mathrm{mL})$ compared with chloroquine $0.49 \mu \mathrm{g} / \mathrm{mL}$.

\subsection{Structure Activity Relationship}

Structure-activity relationship (SAR) revealed that pyrimidine-2-thione moieties incorporating tetrazolo, methyltetrazolo or quinolinone substituents at position 4 along with an acetyl or ester group at position 5 (compounds $4 \mathbf{b}, \mathbf{4 g}, 4 \mathbf{i}$ ) have greater potency than the corresponding pyrimidine compounds with the same substituents except compound $4 \mathbf{d}$ which has a lowest effect $\left(\mathrm{IC}_{50}=15.87 \mu \mathrm{g} / \mathrm{mL}\right.$ ). A combination of the three substituents (quinolinone, acetyl, and methyl) at positions 4,5 , and 6 of the pyrimidine-2-thione has the best activity and greater $\left(\mathrm{IC}_{50}=0.041 \mu \mathrm{g} / \mathrm{mL}\right)$ than the corresponding pyrimidine, notably $4 \mathrm{~h}\left(\mathrm{IC}_{50}=2.21 \mu \mathrm{g} / \mathrm{mL}\right)$. 2-Chloroquinoline moiety containing a 1,3,4-oxadiazole residue at position 3 (compound 12) has greater activity $\left(\mathrm{IC}_{50}=0.46 \mu \mathrm{g} / \mathrm{mL}\right.$ ) than the corresponding compounds where ethyl ester, or carbohydrazide groups present at position 3 in compounds $\mathbf{1 0}$ and $\mathbf{1 1}\left(\mathrm{IC}_{50}=1.91 \mu \mathrm{g} / \mathrm{mL}\right.$ and $2.21 \mu \mathrm{g} / \mathrm{mL}$, respectively).

\section{Experimental Section}

\subsection{General Information}

Melting points were determined on digital MFB-595 instrument (Gallenkamp London, UK) using open capillary tubes and are uncorrected. IR spectra were recorded on a FTIR 440 spectrometer (Shimadzu, Tokyo, Japan) using KBr pellets. Mass spectra were obtained on a Qp-2010 plus mass spectrometer (Shimadzu) at $70 \mathrm{eV} .{ }^{1} \mathrm{H}-\mathrm{NMR}$ and ${ }^{13} \mathrm{C}-\mathrm{NMR}$ spectra were recorded on a model Ultra Shield-NMR spectrometer (500 MHz or $400 \mathrm{MHz}$, Bruker, Coventry, UK) in DMSO- $d_{6}$ using tetramethylsilane (TMS) as an internal standard at the College of Science, King Khalid University, Saudi Arabia; chemical shifts are reported as $\delta$ ppm units. The elemental analyses $(\% \mathrm{C}, \mathrm{H}, \mathrm{N})$ were done at the Microanalytical Center, Cairo University, Cairo, Egypt. Solvents were dried by standard techniques. The monitoring of the progress of all reactions and homogeneity of the synthesized compounds was carried out and was run using thin layer chromatography (TLC) aluminum sheets silica gel $60 \mathrm{~F}_{254}$ (Merck, Darmstadt, Germany).

\subsection{Synthesis}

\subsubsection{General Procedure for the Synthesis of Dihydropyrimidines (DHPMs) $\mathbf{4 a} \mathbf{a}-\mathbf{j}$}

A mixture of the appropriate aromatic aldehyde $\mathbf{1 a}-\mathbf{c}(10 \mathrm{mmol})$, ethyl acetoacetate (2a) (or acetylacetone $(\mathbf{2 b}))(10 \mathrm{mmol})$, urea (3a) (or thiourea $(\mathbf{3 b}))(10 \mathrm{mmol})$ in ethanol $(50 \mathrm{~mL})$ in the presence of a catalytic amount of hydrochloric acid was refluxed for 8-12 h (TLC). The precipitated crude was filtered off, washed with ethanol and recrystallized from acetic acid to give pure crystals of DHPMs 4a-j.

Ethyl-6-methyl-2-oxo-4-(tetrazolo[1,5-a]quinolin-4-yl)-1,2,3,4-tetrahydropyrimidine-5-carboxylate (4a) Yellow crystals, m.p. $278-280{ }^{\circ} \mathrm{C}$; IR $\left(\mathrm{cm}^{-1}\right)$ : v 3256 and $3122(2 \mathrm{~N}-\mathrm{H}$ str.), $1725(\mathrm{C}=\mathrm{O}), 1693(\mathrm{C}=\mathrm{O}), 1610$ $(\mathrm{C}=\mathrm{N}), 1556(\mathrm{C}=\mathrm{C}) ;{ }^{1} \mathrm{H}-\mathrm{NMR}\left(\mathrm{DMSO}-d_{6}\right): \delta_{\mathrm{H}} 0.94\left(\mathrm{t}, 3 \mathrm{H}, J=6.6 \mathrm{~Hz}, \mathrm{CH}_{3}\right), 2.29\left(\mathrm{~s}, 3 \mathrm{H}, \mathrm{CH}_{3}\right), 3.99(\mathrm{q}, 2 \mathrm{H}$, $\left.J=6.6 \mathrm{~Hz}, \mathrm{CH}_{2}\right), 5.85(\mathrm{~s}, 1 \mathrm{H}, \mathrm{CH}), 7.74\left(\mathrm{~s}, 1 \mathrm{H}, \mathrm{D}_{2} \mathrm{O}\right.$ exchangeable, $\left.\mathrm{NH}\right), 7.79-8.59(\mathrm{~m}, 5 \mathrm{H}$, quinoline- $\mathrm{H})$, $9.49\left(\mathrm{~s}, 1 \mathrm{H}, \mathrm{D}_{2} \mathrm{O}\right.$ exchangeable, NH) ppm; ${ }^{13} \mathrm{C}-\mathrm{NMR}$ (DMSO- $\left.d_{6}\right): \delta_{\mathrm{C}} 13.88,18.06,52.19,59.07,95.22$, 116.11, 123.56, 128.33, 128.60, 129.33, 129.58, 130.29, 131.29, 146.29, 150.33 (quinoline-C), 151.33 (CONH), 165.01 ( $\mathrm{C}=\mathrm{O}$, ester) ppm; EI-Ms: $m / z$ (\%): 353 [ $\mathrm{M}^{+}+1$ ]. Anal. Calcd for $\mathrm{C}_{17} \mathrm{H}_{16} \mathrm{~N}_{6} \mathrm{O}_{3}$ (352.35.): C, 57.95; $\mathrm{H}, 4.58 ; \mathrm{N}, 23.85$; Found C, 57.80; H, 4.60; N, 23.70 .

Ethyl-6-methyl-4-(tetrazolo[1,5-a]quinolin-4-yl)-2-thioxo-1,2,3,4-tetrahydropyrimidine-5-carboxylate (4b) Yellow crystals, m.p. $263-265^{\circ} \mathrm{C}$; IR $\left(\mathrm{cm}^{-1}\right): v 3275$ and $3146(2 \mathrm{NH}), 1700(\mathrm{C}=\mathrm{O}), 1690(\mathrm{C}=\mathrm{O}), 1612$ $(\mathrm{C}=\mathrm{N}), 1588(\mathrm{C}=\mathrm{C}){ }^{1} \mathrm{H}-\mathrm{NMR}\left(\mathrm{DMSO}-d_{6}\right): \delta_{\mathrm{H}} 1.02\left(\mathrm{t}, 3 \mathrm{H}, J=6.77 \mathrm{~Hz}, \mathrm{CH}_{3}\right), 2.20\left(\mathrm{~s}, 3 \mathrm{H}, \mathrm{CH}_{3}\right), 4.10$ 
$\left(\mathrm{q}, 2 \mathrm{H}, J=6.77 \mathrm{~Hz}, \mathrm{CH}_{2}\right), 5.80(\mathrm{~s}, 1 \mathrm{H}, \mathrm{CH}), 7.74\left(\mathrm{~s}, 1 \mathrm{H}, \mathrm{D}_{2} \mathrm{O}\right.$ exchangeable, $\left.\mathrm{NH}\right), 7.79-8.59(\mathrm{~m}, 5 \mathrm{H}$, quinoline-H), $10.39\left(\mathrm{~s}, 1 \mathrm{H}, \mathrm{D}_{2} \mathrm{O}\right.$ exchangeable, $\mathrm{NH}$ ) ppm; ${ }^{13} \mathrm{C}-\mathrm{NMR}$ (DMSO- $\left.d_{6}\right): \delta_{\mathrm{C}} 13.88,18.06,52.19$, 59.07, 95.22, 116.11, 123.56, 128.33, 128.60, 129.33, 129.58, 130.29, 131.29, 146.29, 150.33 (quinoline-C), 151.33 (CONH), 165.01 (C=O, ester) ppm; EI-Ms: $m / z(\%): 368$ [M $\left.{ }^{+}, 35\right]$; Anal. Calcd for $\mathrm{C}_{17} \mathrm{H}_{16} \mathrm{~N}_{6} \mathrm{O}_{2} \mathrm{~S}$ (368.41): C, 55.42; H, 4.38; N, 22.81; Found C, 55.60; H, 4.50; N, 22.90.

5-Acetyl-6-methyl-4-(tetrazolo[1,5-a]quinolin-4-yl)-3,4-dihydropyrimidin-2(1H)-one (4c) Yellow crystals, m.p. $>300^{\circ} \mathrm{C}$; IR $\left(\mathrm{cm}^{-1}\right)$ : v 3350 and $3294(2 \mathrm{NH}), 1687(\mathrm{C}=\mathrm{O}), 1651(\mathrm{C}=\mathrm{O}), 1622(\mathrm{C}=\mathrm{N}), 1565(\mathrm{C}=\mathrm{C})$; ${ }^{1} \mathrm{H}-\mathrm{NMR}\left(\mathrm{DMSO}-d_{6}\right): \delta_{\mathrm{H}} 2.18\left(\mathrm{~s}, 3 \mathrm{H}, \mathrm{CH}_{3}\right), 2.30\left(\mathrm{~s}, 3 \mathrm{H}, \mathrm{CH}_{3}\right), 5.65(\mathrm{~s}, 1 \mathrm{H}, \mathrm{CH}), 7.20-7.80(\mathrm{~m}, 5 \mathrm{H}$, quinoline-H), $8.01\left(\mathrm{~s}, 1 \mathrm{H}, \mathrm{D}_{2} \mathrm{O}\right.$ exchangeable, $\left.\mathrm{NH}\right), 9.29\left(\mathrm{~s}, 1 \mathrm{H}, \mathrm{D}_{2} \mathrm{O}\right.$ exchangeable, $\left.\mathrm{NH}\right) \mathrm{ppm} ;{ }^{13} \mathrm{C}-\mathrm{NMR}$ (DMSO- $\left.d_{6}\right): \delta_{C} 17.35,29.88,49.50,106.95,116.87,118.89,121.94,128.11,130.22,133.04,134.65,138.09$, 149.12, 150.27 (quinoline-C), $152.26(\mathrm{C}=\mathrm{O}), 193.22(\mathrm{C}=\mathrm{O})$ ppm; EI-Ms: $m / z(\%): 322\left[\mathrm{M}^{+}, 23\right]$; Anal. Calcd for $\mathrm{C}_{16} \mathrm{H}_{14} \mathrm{~N}_{6} \mathrm{O}_{2}$ (322.32): C, 59.62; H, 4.38; N, 26.06; Found C, 59.80; H, 4.20; N, 26.20.

1-(6-Methyl-4-(tetrazolo[1,5-a]quinolin-4-yl)-2-thiooxo-1,2,3,4-tetrahydropyrimidin-5-yl)ethanone (4d) Yellow crystals, m.p. $280-282{ }^{\circ} \mathrm{C}$; IR $\left(\mathrm{cm}^{-1}\right)$ : $v$ 3373, $3172(2 \mathrm{NH}), 1685(\mathrm{C}=\mathrm{O}), 1628(\mathrm{C}=\mathrm{N}), 1588(\mathrm{C}=\mathrm{C})$; ${ }^{1} \mathrm{H}-\mathrm{NMR}\left(\mathrm{DMSO}-d_{6}\right): \delta_{\mathrm{H}} 2.23\left(\mathrm{~s}, 3 \mathrm{H}, \mathrm{CH}_{3}\right), 2.39\left(\mathrm{~s}, 3 \mathrm{H}, \mathrm{CH}_{3}\right), 5.57(\mathrm{~s}, 1 \mathrm{H}, \mathrm{CH}), 7.18-7.77(\mathrm{~m}, 5 \mathrm{H}$, quinoline-H), $7.95\left(\mathrm{~s}, 1 \mathrm{H}, \mathrm{D}_{2} \mathrm{O}\right.$ exchangeable, $\left.\mathrm{NH}\right), 9.44\left(\mathrm{~s}, 1 \mathrm{H}, \mathrm{D}_{2} \mathrm{O}\right.$ exchangeable, $\left.\mathrm{NH}\right) \mathrm{ppm} ;{ }^{13} \mathrm{C}-\mathrm{NMR}$ (DMSO- $d_{6}$ ): $\delta_{\mathrm{C}} 17.88,29.70,49.67,106.17,114.83,118.71,127.40,128.17,130.40,132.46,135.76,138.23$, 146.39, 151.22 (quinoline-C), $161.98(\mathrm{C}=\mathrm{O}), 174.60$ (C=S) ppm; EI-Ms: $m / z(\%): 338$ [M+, 25]; Anal. Calcd for $\mathrm{C}_{16} \mathrm{H}_{14} \mathrm{~N}_{6} \mathrm{OS}$ (338.39): C, 56.79; H, 4.17; N, 24.84; Found C, 56.80; H, 4.30; N, 24.70.

Ethyl-6-methyl-4-(7-methyltetrazolo[1,5-a]quinolin-4-yl)-2-oxo-1,2,3,4-tetrahydropyrimidine-5-carboxylate (4e) Yellow crystals, m.p. $293^{\circ} \mathrm{C}$; IR $\left(\mathrm{cm}^{-1}\right)$ : $v$ 3325, $3271(2 \mathrm{NH}), 1720(\mathrm{CO}$, ester), $1675(\mathrm{C}=\mathrm{O}), 1610(\mathrm{C}=\mathrm{N})$, $1596(\mathrm{C}=\mathrm{C}) ;{ }^{1} \mathrm{H}-\mathrm{NMR}\left(\mathrm{DMSO}-d_{6}\right): \delta_{\mathrm{H}} 1.19\left(\mathrm{t}, 3 \mathrm{H}, J=6.50 \mathrm{~Hz}, \mathrm{CH}_{3}\right), 2.33\left(\mathrm{~s}, 3 \mathrm{H}, \mathrm{CH}_{3}\right), 2.55(\mathrm{~s}, 3 \mathrm{H}$, $\left.\mathrm{CH}_{3}\right), 4.20\left(\mathrm{q}, 2 \mathrm{H}, \mathrm{J}=6.50 \mathrm{~Hz}, \mathrm{CH}_{2}\right), 5.91(\mathrm{~s}, 1 \mathrm{H}, \mathrm{CH}), 7.13\left(\mathrm{~s}, 1 \mathrm{H}, \mathrm{D}_{2} \mathrm{O}\right.$ exchangeable, NH), $7.77(\mathrm{~d}$, $1 \mathrm{H}, J=8.5 \mathrm{~Hz}$, quinoline- $\mathrm{H}), 7.97(\mathrm{~d}, 1 \mathrm{H}, J=8.5 \mathrm{~Hz}$, quinoline- $\mathrm{H}), 8.19(\mathrm{~s}, 1 \mathrm{H}$, quinoline- $\mathrm{H}), 8.46$ $\left(\mathrm{s}, 1 \mathrm{H}\right.$, quinoline-H), $9.55\left(\mathrm{~s}, 1 \mathrm{H}, \mathrm{D}_{2} \mathrm{O}\right.$ exchangeable, $\left.\mathrm{NH}\right) ;{ }^{13} \mathrm{C}-\mathrm{NMR}$ (DMSO- $\left.d_{6}\right): \delta_{\mathrm{C}} 13.91,18.03$, $20.84,52.11,62.49,59.07,95.22,123.63,127.45,128.45,128.96,129.31,129.51,132.62,138.10,145.70$ (quinoline-C), $151.38(\mathrm{CONH}), 157.66\left(\mathrm{C}=\mathrm{O}\right.$, ester) ppm; EI-Ms: $m / z$ (\%): 367 [ $\left.\mathrm{M}^{+}+1,15\right]$, Anal. Calcd for $\mathrm{C}_{18} \mathrm{H}_{18} \mathrm{~N}_{6} \mathrm{O}_{3}$ (366.37): C, 59.01; H, 4.95; N, 22.94; Found C, 59.20; H, 4.90; N, 22.90.

Ethyl-6-methyl-4-(7-methyltetrazolo[1,5-a]quinolin-4-yl)-2-thioxo-1,2,3,4-tetrahydropyrimidine-5-carboxylate (4f) Yellow crystals, m.p. $289^{\circ} \mathrm{C}$; IR $\left(\mathrm{cm}^{-1}\right): v$ 3325, $3271(2 \mathrm{NH}), 1710(\mathrm{C}=\mathrm{O}$, ester), $1683(\mathrm{C}=\mathrm{O}), 1624$ $(\mathrm{C}=\mathrm{N}), 1596(\mathrm{C}=\mathrm{C}) ;{ }^{1} \mathrm{H}-\mathrm{NMR}\left(\mathrm{DMSO}-d_{6}\right): \delta_{\mathrm{H}} 1.24\left(\mathrm{t}, 3 \mathrm{H}, J=6.55 \mathrm{~Hz}, \mathrm{CH}_{3}\right), 2.33\left(\mathrm{~s}, 3 \mathrm{H}, \mathrm{CH}_{3}\right), 2.55(\mathrm{~s}$, $\left.3 \mathrm{H}, \mathrm{CH}_{3}\right), 4.10\left(\mathrm{q}, 2 \mathrm{H}, J=6.55 \mathrm{~Hz}, \mathrm{CH}_{2}\right), 5.85(\mathrm{~s}, 1 \mathrm{H}, \mathrm{CH}), 7.80\left(\mathrm{~s}, 1 \mathrm{H}, \mathrm{D}_{2} \mathrm{O}\right.$ exchangeable, NH), $7.82(\mathrm{~d}$, $1 \mathrm{H}, J=8.7 \mathrm{~Hz}$, quinoline- $\mathrm{H}), 8.01(\mathrm{~d}, 1 \mathrm{H}, J=8.7 \mathrm{~Hz}$, quinoline- $\mathrm{H}), 8.11(\mathrm{~s}, 1 \mathrm{H}$, quinoline- $\mathrm{H}), 8.50(\mathrm{~s}, 1 \mathrm{H}$, quinoline- $\mathrm{H}), 9.59\left(\mathrm{~s}, 1 \mathrm{H}, \mathrm{D}_{2} \mathrm{O}\right.$ exchangeable, $\left.\mathrm{NH}\right),{ }^{13} \mathrm{C}-\mathrm{NMR}\left(\mathrm{DMSO}-d_{6}\right): \delta_{\mathrm{C}} 13.81,17.30,20.84,51.98$, $59.42,115.97,123.67,127.40,128.66,128.96,129.06,129.22,130.84,132.82,138.27,146.59$ (quinoline-C), 157.66 (C=O, ester), 174.55 (C=S) ppm; EI-Ms: $m / z(\%)$ : 382 [M $\left.{ }^{+}, 23\right]$; Anal. Calcd for $\mathrm{C}_{18} \mathrm{H}_{18} \mathrm{~N}_{6} \mathrm{O}_{2} \mathrm{~S}$ (382.44.): C, 56.53; H, 4.74; N, 21.97; Found C, 56.50; H, 4.80; N, 21.80.

1-(6-Methyl-4-(7-methyltetrazolo[1,5-a]quinolin-4-yl)-2-thioxo-1,2,3,4-tetrahydropyrimidine-5-ethanone (4g) Yellow crystals, m.p. $280-282^{\circ} \mathrm{C}$; IR $\left(\mathrm{cm}^{-1}\right)$ : v 3290, $3215(2 \mathrm{NH}), 1700(\mathrm{C}=\mathrm{O}), 1655(\mathrm{C}=\mathrm{O}), 1614(\mathrm{C}=\mathrm{N})$, $1586(\mathrm{C}=\mathrm{C}) ;{ }^{1} \mathrm{H}-\mathrm{NMR}\left(\mathrm{DMSO}-d_{6}\right): \delta_{\mathrm{H}} 2.33\left(\mathrm{~s}, 3 \mathrm{H}, \mathrm{CH}_{3}\right), 2.40\left(\mathrm{~s}, 3 \mathrm{H}, \mathrm{CH}_{3}\right), 2.60\left(\mathrm{~s}, 3 \mathrm{H}, \mathrm{CH}_{3}\right), 5.77(\mathrm{~s}$, $1 \mathrm{H}, \mathrm{CH}), 7.49\left(\mathrm{~s}, 1 \mathrm{H}, \mathrm{D}_{2} \mathrm{O}\right.$ exchangeable, $\left.\mathrm{NH}\right), 7.77(\mathrm{~d}, 1 \mathrm{H}, J=9 \mathrm{~Hz}$, quinoline- $\mathrm{H}), 7.99(\mathrm{~d}, 1 \mathrm{H}$, $J=9 \mathrm{~Hz}$, quinoline- $\mathrm{H}), 8.10(\mathrm{~s}, 1 \mathrm{H}$, quinoline- $\mathrm{H}), 8.50(\mathrm{~s}, 1 \mathrm{H}$, quinoline- $\mathrm{H}), 9.44\left(\mathrm{~s}, 1 \mathrm{H}, \mathrm{D}_{2} \mathrm{O}\right.$ exchangeable, $\mathrm{NH}$ ); ${ }^{13} \mathrm{C}-\mathrm{NMR}$ (DMSO- $\left.d_{6}\right): \delta_{\mathrm{C}} 17.81,20.84,29.18,50.98,106.17,114.83,118.71,128.17$, 130.40, 132.46, 135.76, 136.4, 138.23, 146.39, 151.22 (quinoline-C), 174.60 (C=S), 192.20 (C=O) ppm; EI-Ms: $m / z(\%): 352$ [M $\left.\mathrm{M}^{+}, 45\right]$; Anal. Calcd for $\mathrm{C}_{17} \mathrm{H}_{16} \mathrm{~N}_{6} \mathrm{OS}$ (352.41.): C, 57.94; $\mathrm{H}, 4.58 ; \mathrm{N}, 23.85$; Found C, 57.80; H, 4.70; N, 23.80 .

3-(5-Acetyl-6-methyl-2-oxo-1,2,3,4-tetrahydropyridin-4yl)quinolin-2(1H)-one $(\mathbf{4 h})$ Yellow crystals, m.p. $>300{ }^{\circ} \mathrm{C}$; IR $\left(\mathrm{cm}^{-1}\right): v 3301,3224,3180(3 \mathrm{NH}), 1700(\mathrm{C}=\mathrm{O}), 1649(\mathrm{C}=\mathrm{O}), 1618(\mathrm{C}=\mathrm{N}), 1583$ 
$(\mathrm{C}=\mathrm{C}) ;{ }^{1} \mathrm{H}-\mathrm{NMR}\left(\mathrm{DMSO}-d_{6}\right): \delta_{\mathrm{H}} 2.16\left(\mathrm{~s}, 3 \mathrm{H}, \mathrm{CH}_{3}\right), 2.35\left(\mathrm{~s}, 3 \mathrm{H}, \mathrm{CH}_{3}\right), 5.44(\mathrm{~s}, 1 \mathrm{H}, \mathrm{CH}), 7.16-8.04(\mathrm{~m}$, $4 \mathrm{H}$, quinoline- $\mathrm{H}), 8.32(\mathrm{~s}, 1 \mathrm{H}$, quinoline- $\mathrm{H}), 9.24\left(\mathrm{~s}, 1 \mathrm{H}, \mathrm{D}_{2} \mathrm{O}\right.$ exchangeable, $\left.\mathrm{NH}\right), 11.97\left(\mathrm{~s}, 1 \mathrm{H}, \mathrm{D}_{2} \mathrm{O}\right.$ exchangeable, $\mathrm{NH}), 12.31\left(\mathrm{~s}, 1 \mathrm{H}, \mathrm{D}_{2} \mathrm{O}\right.$ exchangeable, $\left.\mathrm{NH}\right) ;{ }^{13} \mathrm{C}-\mathrm{NMR}$ (DMSO- $\left.d_{6}\right): \delta_{\mathrm{C}} 18.35,29.91,49.25$, 106.95, 114.87, 118.89, 121.94, 128.11, 130.22, 133.04, 134.65, 138.09, 149.12 (quinoline-C), $152.26(\mathrm{C}=\mathrm{O})$, $161.32(\mathrm{C}=\mathrm{O}), 194.22(\mathrm{C}=\mathrm{O})$ ppm; EI-Ms: $m / z(\%): 297$ [ $\mathrm{M}^{+}$]; Anal. Calcd for $\mathrm{C}_{16} \mathrm{H}_{15} \mathrm{~N}_{3} \mathrm{O}_{3}$ (297.31.): $\mathrm{C}$, 64.64; H, 5.09; N, 14.13; Found C, 64.50; H, 5.20; N, 14.20.

3-(5-Acetyl-6-methyl-2-thioxo-1,2,3,4-tetrahydropyrimidin-4yl)quinolin-2(1H)-one (4i) Yellow crystals, m.p. $>300{ }^{\circ} \mathrm{C}$; IR $\left(\mathrm{cm}^{-1}\right): v$ 3299, 3234, $3172(3 \mathrm{NH}), 1651(\mathrm{C}=\mathrm{O}), 1610(\mathrm{C}=\mathrm{N}), 1590(\mathrm{C}=\mathrm{C}) ;{ }^{1} \mathrm{H}-\mathrm{NMR}$ (DMSO- $\left.d_{6}\right): \delta_{\mathrm{H}} 2.20\left(\mathrm{~s}, 3 \mathrm{H}, \mathrm{CH}_{3}\right), 2.30\left(\mathrm{~s}, 3 \mathrm{H}, \mathrm{CH}_{3}\right), 5.50(\mathrm{~s}, 1 \mathrm{H}, \mathrm{CH}), 7.16-7.95(\mathrm{~m}, 4 \mathrm{H}$, quinoline- $\mathrm{H})$, $8.20(\mathrm{~s}, 1 \mathrm{H}$, quinoline- $\mathrm{H}), 9.11\left(\mathrm{~s}, 1 \mathrm{H}, \mathrm{D}_{2} \mathrm{O}\right.$ exchangeable, $\left.\mathrm{NH}\right), 11.82\left(\mathrm{~s}, 1 \mathrm{H}, \mathrm{D}_{2} \mathrm{O}\right.$ exchangeable, $\left.\mathrm{NH}\right)$, $12.20\left(\mathrm{~s}, 1 \mathrm{H}, \mathrm{D}_{2} \mathrm{O}\right.$ exchangeable, $\left.\mathrm{NH}\right) ;{ }^{13} \mathrm{C}-\mathrm{NMR}\left(\mathrm{DMSO}-d_{6}\right): \delta_{\mathrm{C}} 17.19,49.78,59.42,104.66,114.83$, 118.71, 127.40, 128.17, 129.23, 130.40, 132.46, 135.76, 138.23, 146.39 (quinoline-C), 164.67 (C=O), 174.50 (C=S) ppm; EI-Ms: $m / z$ (\%): 313 [M $\mathrm{M}^{+}$; Anal. Calcd for $\mathrm{C}_{16} \mathrm{H}_{15} \mathrm{~N}_{3} \mathrm{O}_{2} \mathrm{~S}$ (313.37): C, 61.37; $\mathrm{H}, 4.82 ; \mathrm{N}$, 13.41; Found C, 61.20; H, 4.70; N, 13.20.

Ethyl-6-methyl-4-(2-oxo-1,2-dihydroquinolin-3-yl)-2-thioxo-1,2,3,4-tetrahydropyrimidine-5-carboxylate (4j) Yellow crystals, m.p. $>300{ }^{\circ} \mathrm{C}$; IR $\left(\mathrm{cm}^{-1}\right): \vee 3377,3224,3186(3 \mathrm{NH}), 1780(\mathrm{C}=\mathrm{O}$, ester $), 1660(\mathrm{C}=\mathrm{O})$, $16118(\mathrm{C}=\mathrm{N}), 1566(\mathrm{C}=\mathrm{C}) ;{ }^{1} \mathrm{H}-\mathrm{NMR}\left(\mathrm{DMSO}-d_{6}\right): \delta_{\mathrm{H}} 1.08\left(\mathrm{t}, 3 \mathrm{H}, J=7 \mathrm{~Hz}, \mathrm{CH}_{3}\right), 2.36\left(\mathrm{~s}, 3 \mathrm{H}, \mathrm{CH}_{3}\right), 4.01$ $\left(\mathrm{q}, 2 \mathrm{H}, J=7 \mathrm{~Hz}, \mathrm{CH}_{2}\right), 5.41(\mathrm{~s}, 1 \mathrm{H}, \mathrm{CH}), 7.17(\mathrm{dd}, 1 \mathrm{H}, J=1 \mathrm{~Hz}, J=8 \mathrm{~Hz}$, quinoline-H), $7.49(\mathrm{dd}, 1 \mathrm{H}$, $J=1.35 \mathrm{~Hz}, J=7.25 \mathrm{~Hz}$, quinoline-H), $7.53(\mathrm{dd}, 1 \mathrm{H}, J=1.5 \mathrm{~Hz}, J=9 \mathrm{~Hz}$, quinoline- $\mathrm{H}), 7.71(\mathrm{dd}, 1 \mathrm{H}$, $J=2 \mathrm{~Hz}, J=8.2 \mathrm{~Hz}), 7.72\left(\mathrm{~s}, 1 \mathrm{H}\right.$, quinoline-H), $9.01\left(\mathrm{~s}, 1 \mathrm{H}, \mathrm{D}_{2} \mathrm{O}\right.$ exchangeable, $\left.\mathrm{NH}\right), 10.33(\mathrm{~s}, 1 \mathrm{H}$, $\mathrm{D}_{2} \mathrm{O}$ exchangeable, $\left.\mathrm{NH}\right), 11.90\left(\mathrm{~s}, 1 \mathrm{H}, \mathrm{D}_{2} \mathrm{O}\right.$ exchangeable, $\left.\mathrm{NH}\right) ;{ }^{13} \mathrm{C}-\mathrm{NMR}$ (DMSO- $\left.d_{6}\right): \delta_{\mathrm{C}} 14.01,17.19$, 49.78, 59.42, 97.97, 114.83, 118.71, 127.40, 128.17, 130.40, 132.46, 135.76, 138.23, 146.39 (quinoline-C), 160.80 (C=O, ester) ,164.98 (C=O), $174.64(\mathrm{C}=\mathrm{S})$ ppm; EI-Ms: $m / z$ (\%): 343.95 [M+1, 35], Anal. Calcd for $\mathrm{C}_{17} \mathrm{H}_{17} \mathrm{~N}_{3} \mathrm{O}_{3} \mathrm{~S}$ (343.40.): C, 59.46; H, 4.99; N, 12.24; Found $\mathrm{C}, 59.50 ; \mathrm{H}, 4.80 ; \mathrm{N}, 12.20$.

\subsubsection{General Procedure for the Synthesis of Chalcones $\mathbf{6 a}, \mathbf{b}$}

To a stirred solution of acetophenone $(5 \mathbf{a})$ or 2-acetylthiophene $(5 \mathbf{b})(10 \mathrm{mmol})$ in alcoholic $\mathrm{NaOH}$ solution $(5 \%, 25 \mathrm{~mL})$ at $0-5{ }^{\circ} \mathrm{C}$ a solution of 2-(piperidin-1-yl) quinoline-3-carbaldehyde (1e) $(2.40 \mathrm{~g}$, $10 \mathrm{mmol}$ ) was added gradually. Stirring was continued for $24 \mathrm{~h}$ at r.t. the resulting precipitate was filtrated, washed with EtOH $(10 \mathrm{~mL})$, and dried, and crystallized from ethanol.

1-Phen.yl-3-[2-(piperidin-1-yl)quinolin-3-yl]prop-2-en-1-one (6a). Yellow crystals, m.p. 127-129 ${ }^{\circ} \mathrm{C}, \mathrm{IR}$ $\left(\mathrm{cm}^{-1}\right): v 1654(\mathrm{C}=\mathrm{O}), 1585(\mathrm{C}=\mathrm{C}) ;{ }^{1} \mathrm{H}-\mathrm{NMR}\left(\mathrm{CDCl}_{3}\right): \delta_{\mathrm{H}} 1.62-1.77\left(\mathrm{~m}, 6 \mathrm{H}, \mathrm{CH}_{2}\right.$-piperidinyl), 3.30-3.34 (m, $4 \mathrm{H}, \mathrm{CH}_{2}$-piperidinyl), $6.94(\mathrm{~d}, 1 \mathrm{H}, J=18.90 \mathrm{~Hz}, \mathrm{CH}=\mathrm{CH}), 7.40-7.79(\mathrm{~m}, 10 \mathrm{H}$, quinoline-H \& Ar- $\mathrm{H}$ \& $\mathrm{CH}=\mathrm{CH}), 8.14$ (s, $1 \mathrm{H}$, quinoline-H); EI-Ms: $m / z(\%)$ : 342 [M $\left.\mathrm{M}^{+}, 60\right]$; Anal. Calcd for $\mathrm{C}_{23} \mathrm{H}_{22} \mathrm{~N}_{2} \mathrm{O}$ (342.43.): C, 80.67; H, 6.48; N, 8.18; Found C, 80.50; H, 6.60; N, 8.20.

3-[2-(Piperidin-1-yl)quinolin-3-yl]-1-thiophene-2-yl)prop-2-en-1-one (6b). Yellow crystals, m.p. $162-164{ }^{\circ} \mathrm{C}$ $(\mathrm{EtOH}) ; \mathrm{IR}\left(\mathrm{cm}^{-1}\right): v 1649(\mathrm{C}=\mathrm{O}), 1595(\mathrm{C}=\mathrm{C}) ;{ }^{1} \mathrm{H}-\mathrm{NMR}\left(\mathrm{CDCl}_{3}\right): \delta_{\mathrm{H}} 1.66-1.80\left(\mathrm{~m}, 6 \mathrm{H}, \mathrm{CH}_{2}\right.$-piperidinyl), 3.34-3.36 (m, 4H, $\mathrm{CH}_{2}$-piperidinyl), 7.19-7.92 (m, 8H, quinoline- $\mathrm{H}$, thiophene- $\left.\mathrm{H}, \mathrm{CH}=\mathrm{CH}\right), 8.02(\mathrm{~d}$, $1 \mathrm{H}, J=19.2 \mathrm{~Hz}, \mathrm{CH}=\mathrm{CH}), 8.21(\mathrm{~s}, 1 \mathrm{H}$, quinoline- $\mathrm{H}) ;{ }^{13} \mathrm{C}-\mathrm{NMR}\left(\mathrm{CDCl}_{3}\right): \delta_{\mathrm{C}} 24.59,25.88,51.83,122.17$, 122.94, 124.32, 127.36, 128.31, 128.38, 130.49, 131.84.132.19, 132.95, 133.99, 137.26, 141.80, 145.48, 160.61(thiophene-C \& quinoline-C), 181.97 (C=O) ppm; EI-Ms: $m / z$ (\%): 348 [M ${ }^{+}, 74$ ], Anal. Calcd for $\mathrm{C}_{21} \mathrm{H}_{20} \mathrm{~N}_{2} \mathrm{OS}$ (348.46.): $\mathrm{C}, 72.38 ; \mathrm{H}, 5.79 ; \mathrm{N}, 8.04 ;$ Found C, 72.40; H, 5.70; N, 8.10.

\subsubsection{General Procedure for the Synthesis of $\mathbf{7 a}, \mathbf{b}$}

A mixture of $6 \mathbf{a}, \mathbf{b}(10 \mathrm{mmol})$ and ethyl cyanoacetate $(1.13 \mathrm{~mL}, 10 \mathrm{mmole})$ in absolute ethanol $(20 \mathrm{~mL})$ in the presence of a few drops of piperidine was stirred at room temperature for $6 \mathrm{~h}$. The solid formed was filtered off, washed with ethanol, dried and crystallized from acetic acid. 
Ethyl-2-oxo-6-phenyl-4-[2-(piperidin-1-yl)quinolin-3-yl]-2H-pyran-3-carboxylate (7a). Colorless crystals, m.p. $174-176{ }^{\circ} \mathrm{C}$; IR $\left(\mathrm{cm}^{-1}\right)$ : v $1736(\mathrm{C}=\mathrm{O}), 1681(\mathrm{C}=\mathrm{O}), 1595(\mathrm{C}=\mathrm{C}) ;{ }^{1} \mathrm{H}-\mathrm{NMR}\left(\mathrm{CDCl}_{3}\right): \delta_{\mathrm{H}} 1.38(\mathrm{t}$, $\left.3 \mathrm{H}, J=7.5 \mathrm{~Hz}, \mathrm{CH}_{3}\right), 1.69-1.89\left(\mathrm{~m}, 6 \mathrm{H}, \mathrm{CH}_{2}\right.$-piperidinyl), 3.53-3.57 (m, 4H, $\mathrm{CH}_{2}$-piperidinyl), 4.35 (q, $\left.2 \mathrm{H}, J=7.5 \mathrm{~Hz}, \mathrm{CH}_{2}\right), 7.39(\mathrm{~s}, 1 \mathrm{H}$, pyran $\mathrm{H}-5), 7.52-7.93(\mathrm{~m}, 9 \mathrm{H}$, Ar-H \& quinoline-H), $8.06(\mathrm{~s}, 1 \mathrm{H}$, quinoline-H); ${ }^{13} \mathrm{C}-\mathrm{NMR}\left(\mathrm{CDCl}_{3}\right): \delta_{\mathrm{C}} 14.05,24.45,26.33,52.66,62.68,115.20,116.09,125.17,125.75$, $127.38,127.56,127.72,128.07,128.17,128.31,128.88,129.47,133.74,133.81,134.74,136.21,136.33$, 146.71, 161.52 (thiophene-C \& quinoline-C), 165.56 (C=O), 196.49 (CO, ester) ppm; EI-Ms: $m / z$ (\%): $356\left[\mathrm{M}^{+}+2\right.$, 100]; Anal. Calcd for $\mathrm{C}_{28} \mathrm{H}_{26} \mathrm{~N}_{2} \mathrm{O}_{4}$ (454.52.): $\mathrm{C}, 73.99 ; \mathrm{H}, 5.77 ; \mathrm{N}, 6.16$; Found C, 73.90; $\mathrm{H}$, $5.70 ; \mathrm{N}, 6.10$.

Ethyl-2-oxo-4-[2-(piperidin-1-yl)quinolin-3yl]-6-(thiophen-2-yl)-2H-pyran-3-carboxylate (7b). Colorless crystals, m.p. $154-156^{\circ} \mathrm{C}$; IR $\left(\mathrm{cm}^{-1}\right)$ : v $1743(\mathrm{CO}), 1662(\mathrm{C}=\mathrm{O}), 1596(\mathrm{C}=\mathrm{C}) .{ }^{1} \mathrm{H}-\mathrm{NMR}\left(\mathrm{CDCl}_{3}\right): \delta_{\mathrm{H}} 1.34$ $\left(\mathrm{t}, 3 \mathrm{H}, J=6.95 \mathrm{~Hz}, \mathrm{CH}_{3}\right), 1.65-1.80\left(\mathrm{~m}, 6 \mathrm{H}, \mathrm{CH}_{2}\right.$-piperidinyl), 3.50-3.59 (m, 4H, $\mathrm{CH}_{2}$-piperidinyl), 4.30 $\left(\mathrm{q}, 2 \mathrm{H}, J=6.95 \mathrm{~Hz}, \mathrm{CH}_{2}\right), 7.33(\mathrm{~s}, 1 \mathrm{H}$, pyran $\mathrm{H}-5), 7.40-8.06(\mathrm{~m}, 7 \mathrm{H}$, quinoline-H \& thiophene-H), 8.20 (s, $1 \mathrm{H}$, quinoline-H); EI-Ms: $m / z$ (\%): 461 [ $\mathrm{M}^{+}+1$, 78], Anal. Calcd for $\mathrm{C}_{26} \mathrm{H}_{24} \mathrm{~N}_{2} \mathrm{O}_{4} \mathrm{~S}$ (460.54.): $\mathrm{C}, 67.81$; H, 5.25; N, 6.08; Found C, 67.80; H, 5.400; N, 6.20.

Ethyl-1-amino-2-oxo-6-phenyl-4-(2-(piperidin-1-yl)quinolin-3-yl)-1,2-dihydropyridine-3-carboxylate (8). A mixture of $7 \mathrm{~b}(4.6 \mathrm{~g}, 10 \mathrm{mmol})$ and hydrazine hydrate $(10 \mathrm{mmol})$ in absolute ethanol $(20 \mathrm{~mL})$ was stirred at refluxed temperature for $8 \mathrm{~h}$. The formed solid was filtered off, washed with ethanol, dried and crystallized from acetic acid to give as colorless crystals, m.p. $184-186{ }^{\circ} \mathrm{C},(80 \%$, yield) IR $\left(\mathrm{cm}^{-1}\right): \vee 3383,3182\left(\mathrm{NH}_{2}\right), 1690(\mathrm{C}=\mathrm{O}), 1656(\mathrm{C}=\mathrm{O}), 1588(\mathrm{C}=\mathrm{C}) ;{ }^{1} \mathrm{H}-\mathrm{NMR}\left(\mathrm{DMSO}-d_{6}\right): \delta_{\mathrm{H}} 1.19(\mathrm{t}, 3 \mathrm{H}$, $\left.J=6.67 \mathrm{~Hz}, \mathrm{CH}_{3}\right), 1.73-1.84\left(\mathrm{~m}, 6 \mathrm{H}, \mathrm{CH}_{2}\right.$-piperidinyl), 3.33-3.43 (m, 4H, $\mathrm{CH}_{2}$-piperidinyl), $4.44(\mathrm{q}, 2 \mathrm{H}$, $\left.J=6.67 \mathrm{~Hz}, \mathrm{CH}_{2}\right), 5.41\left(\mathrm{~s}, 2 \mathrm{H}, \mathrm{D}_{2} \mathrm{O}\right.$ exchangeable, $\left.\mathrm{NH}_{2}\right), 6.70(\mathrm{~s}, 1 \mathrm{H}$, pyran $\mathrm{H}-4), 7.59-7.92(\mathrm{~m}, 9 \mathrm{H}, \mathrm{Ar}-\mathrm{H}$ \& quinoline-H), $8.79\left(\mathrm{~s}, 1 \mathrm{H}\right.$, quinoline-H); ${ }^{13} \mathrm{C}-\mathrm{NMR}$ (DMSO- $\left.d_{6}\right): \delta_{\mathrm{C}} 18.52,23.42,26.34,52.67,56.00$, 125.47, 126.77, 126.97, 127.01, 127.27, 127.73,127.87, 127.93, 128.79, 128.83, 129.88, 131.11, 132,19, 134.28, $136.09,137.74,139.34,144.87,145.40$ (Ar-C \& quinoline-C), $150.26(\mathrm{C}=\mathrm{O}), 165.66$ (C=O) ppm; EI-Ms: $m / z(\%): 468$ [M $\left.\mathrm{M}^{+}, 25\right]$, Anal. Calcd for $\mathrm{C}_{28} \mathrm{H}_{28} \mathrm{~N}_{4} \mathrm{O}_{3}$ (468.54): C, 71.78; $\mathrm{H}, 6.02 ; \mathrm{N}, 11.96$; Found C, 71.57; $\mathrm{H}, 6$; N, 11.98 .

Ethyl-2-chloroquinolin-3- carboxylate (10). To a solution of 2-chloroquinoline-3-carboxylic acid $(9,2.07 \mathrm{~g}, 10 \mathrm{mmol})$ in absolute ethanol $(50 \mathrm{~mL}), 5$ drops of conc. $\mathrm{H}_{2} \mathrm{SO}_{4}$ were added and the reaction mixture was heated under reflux for $8 \mathrm{~h}$. The solution was poured onto crushed ice water; the precipitate was filtered, washed with water, dried and recrystallized from ethanol to afford 10. White crystals, 82\% yield, m.p. $295-297{ }^{\circ} \mathrm{C}$; IR $\left(\mathrm{cm}^{-1}\right)$ : $\vee 1716(\mathrm{C}=\mathrm{O}), 1611(\mathrm{C}=\mathrm{N}), 1596(\mathrm{C}=\mathrm{C}) ;{ }^{1} \mathrm{H}-\mathrm{NMR}$ $\left(\mathrm{CDCl}_{3}\right): \delta_{\mathrm{H}} 1.3\left(\mathrm{t}, 3 \mathrm{H}, J=7.25 \mathrm{~Hz}, \mathrm{CH}_{3}\right), 4.34\left(\mathrm{q}, 2 \mathrm{H}, J=7.25 \mathrm{~Hz}, \mathrm{CH}_{2}\right), 7.38-8.12(\mathrm{~m}, 4 \mathrm{H}$, quinoline- $\mathrm{H})$, $8.54\left(\mathrm{~s}, 1 \mathrm{H}\right.$, quinoline-H) ppm; EI-Ms: $m / z(\%): 235\left[\mathrm{M}^{+}, 100\right], 237\left[\mathrm{M}^{+}+2,33\right]$; Anal. Calcd for $\mathrm{C}_{12} \mathrm{H}_{10} \mathrm{ClNO}_{2}$ (235.67): C, 61.16; H, 4.28; N, 5.94; Found C, 61.30; H, 4.40; N, 5.80.

2-Chloroquinoline-3-carbohydrazide (11). A solution of ester derivative 10 (2.35 g, $10 \mathrm{mmol}$,) and hydrazine hydrate $(10 \mathrm{~mL})$ in absolute ethanol $(50 \mathrm{~mL})$ was refluxed for $12 \mathrm{~h}$. The solution was cooled to room temperature, poured onto cooled water, the resulting precipitate was filtered, washed with water, $(3 \times 20 \mathrm{~mL})$ dried and recrystallized from ethanol to give $\mathbf{1 1}$ as a white crystals in $76 \%$ yield, m.p. $>300^{\circ} \mathrm{C}$; IR $\left(\mathrm{cm}^{-1}\right)$ : $\vee ~ 3409,3309\left(\mathrm{NH}_{2}\right), 3135(\mathrm{NH}), 1652(\mathrm{C}=\mathrm{O}), 1611(\mathrm{C}=\mathrm{N}), 1585(\mathrm{C}=\mathrm{C})$, ${ }^{1} \mathrm{H}-\mathrm{NMR}\left(\mathrm{CDCl}_{3}\right): \delta_{\mathrm{H}} 4.60\left(\mathrm{~s}\right.$, brs., $2 \mathrm{H}, \mathrm{D}_{2} \mathrm{O}$ exchangeable, $\left.\mathrm{NH}_{2}\right), 7.48-7.54(\mathrm{dd}, 1 \mathrm{H}, J=1.60 \mathrm{~Hz}, J=8.99$ $\mathrm{Hz}$, quinoline- $\mathrm{H}), 7.70-7.75(\mathrm{~m}, 1 \mathrm{H}$, quinoline- $\mathrm{H}), 8.01-8.06(\mathrm{dd}, 1 \mathrm{H}, J=2.1 \mathrm{~Hz}, J=8.6 \mathrm{~Hz}$, quinoline- $\mathrm{H})$, 8.85 (s, $1 \mathrm{H}$, quinoline- $\mathrm{H}), 9.25$ (s, $1 \mathrm{H}, \mathrm{D}_{2} \mathrm{O}$ exchangeable, $\left.\mathrm{NH}\right) \mathrm{ppm}$; EI-Ms: $m / z(\%): 223\left[\mathrm{M}^{+}+2,26\right]$, 221 [M+ , 9]; Anal. Calcd for $\mathrm{C}_{10} \mathrm{H}_{8} \mathrm{ClN}_{3} \mathrm{O}$ (221.64): C, 54.19; H, 3.64; N, 18.96; Found C, 54.30; H, 3.50; $\mathrm{N}, 18.80$.

5-(2-Chloroquinolin-3-yl)-1,3,4-oxadiazole-2)-thiol (12). To a solution of $\mathbf{1 1}$ (2.21 g, $10 \mathrm{mmol})$ in ethanol $(10 \mathrm{~mL})$ was added carbon disulfide $(50 \mathrm{mmol})$ and potassium hydroxide $(0.65 \mathrm{~g}, 10 \mathrm{mmol})$ at $0{ }^{\circ} \mathrm{C}$. The resulting solution was refluxed for $4 \mathrm{~h}$. The solvent was evaporated and the residue dissolved 
in water and acidified with a diluted solution of $\mathrm{HCl}$. The resulting precipitate was filtered, washed with water, dried and recrystallized from ethanol to afford compound 12. Yield 78\%, Colorless crystals, m.p. $278-280{ }^{\circ} \mathrm{C}$, IR $\left(\mathrm{cm}^{-1}\right): 2500 \mathrm{~cm}^{-1}\left(-\mathrm{SH}\right.$, stretching), $1612(\mathrm{C}=\mathrm{N}), 1598(\mathrm{C}=\mathrm{C}) ;{ }^{1} \mathrm{H}-\mathrm{NMR}$ $\left(\mathrm{DMSO}-d_{6}\right): \delta_{\mathrm{H}} 7.38-7.42(\mathrm{dd}, 1 \mathrm{H}, J=2.1 \mathrm{~Hz}, J=8.6 \mathrm{~Hz}$, quinoline-H), 7.505-7.522 $(\mathrm{d}, 1 \mathrm{H}, J=8 \mathrm{~Hz}$, quinoline-H), $7.75-7.79(\mathrm{dd}, 1 \mathrm{H}, J=1.5 \mathrm{~Hz}, J=7 \mathrm{~Hz}$ quinoline-H), 8.03-8.04 (dd, $1 \mathrm{H}, J=1.5 \mathrm{~Hz}$, $J=8 \mathrm{~Hz}$, quinoline-H), $8.96\left(\mathrm{~s}, 1 \mathrm{H}\right.$, quinoline-H) $13.4(\mathrm{~s}, 1 \mathrm{H}, \mathrm{SH}) ;{ }^{13} \mathrm{C}-\mathrm{NMR}\left(\mathrm{DMSO}-d_{6}\right): \delta_{\mathrm{C}} 115.98$, 116.14, 116.30, 117.56, 119.18, 123.67, 123.83, 123.99, 130.17, 130.33, 133.85, 134.01, 139.38, 146.36, 146.52, 163.94, 164.54 (C2-1,3,4-oxadiazole) ppm; EI-Ms: $m / z$ (\%): $265\left[\mathrm{M}^{+}+2,11\right], 263$ [M $\left.{ }^{+}, 33\right]$; Anal. Calcd for $\mathrm{C}_{11} \mathrm{H}_{6} \mathrm{ClN}_{3} \mathrm{OS}$ (263.70): C, 50.10; H, 2.29; N, 15.39; Found C, 50.30; H, 2.40; N, 15.20.

\subsection{Anti-Plasmodial Assay}

Blood sample infected with the malaria parasite P. falciparum strain was obtained from King Fahd Hospital in Jazan. Parasitemia was measured by examining 1500 red cells with microscopic inspection of Giemsa-stained thin blood smears and is reported as the percent of parasitized erythrocytes. The parasitisma in sample was 3.3\%. In vitro experiments were conducted to measure inhibition of parasite growth after incubation of human parasitized red blood cells in media of Roswell Park Memorial Institute (RPMI 1640) and fetal calf serum. Briefly, this procedure involved preparing stock solutions of each compound in dimethyl sulfoxide (DMSO). The stock solutions were diluted to provide test solutions having concentrations in the range $0.078-5.0 \mu \mathrm{g} / \mathrm{mL}$. Test solutions were transferred to 96-well test plates containing parasitized red blood cells with 3.3\% parasitaemia. Each sample was evaluated in triplicate and the test plate was incubated for $48 \mathrm{~h}$ at $37^{\circ} \mathrm{C}$. After incubation, quantification of parasites was achieved by optical microscopy on blood smears from each well [29]. The blood films were fixed with methanol alcohol and transferred into a stand and immersed in Giemsa's stain for $30 \mathrm{~min}$, then washed with tape water and kept to dry until microscopic examination. The ring and schizont forms were counted. Inhibition percentage was calculated using the following formula: Parasite number of control well-Parasite number of treated well/Parasite number of control well $\times 100$.

\subsection{Statistical Analysis}

Statistical analysis of the data was carried out according to the method of Lentner [30]. $\mathrm{IC}_{50}$ values were calculated using multiple linear regressions [31].

\section{Conclusions}

A series of new quinoline derivatives has been synthesized starting from tetrazoloquinoline-3carbaldehyde, 2-oxo-1,2-dihydroquinoline-3-carbaldehyde, 2-chloroquinoline-3-carbaldehyde, and 2-(piperidin-1-yl)quinoline-3-carbaldehyde. In vitro antimalarial evaluation of the synthesized compounds showed moderate to high antimalarial activities, with $\mathrm{IC}_{50}$ values ranging from 0.014-15.87 $\mu \mathrm{g} / \mathrm{mL}$. The presence of acetyl groups along with 2-thiooxo-1,2,3,4-tetrahydropyrimidine and 1,3,5-oxadiazole residues incorporating quinoline moieties is responsible for increasing the antimalarial activity compared with classical antimalarial agents (chloroquine).

Acknowledgments: The authors are thankful to the Deanship of Scientific Research, Jazan University, Saudi Arabia for the financial support via project No: 1434-G5-19.

Author Contributions: Research design: Rizk E. Khidre; Emad M. El-Telbani, Ibrahim Ali M. Radini Literature review: Rizk E. Khidre; Emad M. El-Telbani, and Ibrahim Ali M. Radini Conducted experiments, Tarek M.Y. Elsheikh Conducted antimalarial: Rizk E. Khidre; Emad M. El-Telbani, Ibrahim Ali M. Radini; Data analysis: Rizk E. Khidre; Emad M. El-Telbani, Ibrahim Ali M. Radini i; Manuscript writing (wrote and contributed): Rizk E. Khidre; Emad M. El-Telbani, Ibrahim Ali M. Radini and Tarek M.Y. Elsheikh. The Authors disclose no actual or potential conflict of interest, and have approved the article.

Conflicts of Interest: The authors declare no conflict of interest. 


\section{References}

1. World Health Organization. WHO Expert Committee on Malaria: Twentieth Report, Technical Report 892. 2000. Available online: http://www.who.int/iris/handle/10665/42247\#sthash.rpqlEh0j.dpuf (accessed on 12 July 2016).

2. World Health Organization. World Malaria Report; WHO: Geneva, Switzerland, 2012; Available online: http://www.who.int/malaria/publications/world_malaria_report_2012/en/ (accessed on 12 July 2016).

3. Marques, M.M.; Costa, M.R.F.; Santana Filho, F.S.; Vieira, J.L.F.; Nascimento, M.T.S.; Brasil, L.W.; Nogueira, F.; Silveira, H.; Reyes-Lecca, R.B.; Monteiro, W.M.; et al. Plasmodium vivax Chloroquine Resistance and Anemia in the Western Brazilian Amazon. Antimicrob. Agents Chemother. 2013, 58, 342-347. [CrossRef] [PubMed]

4. Cruz, L.R.; Spangenberg, T.; Lacerda, M.V.G.; Wells, T.N.C. Malaria in South America: A drug discovery perspective. Malaria J. 2013, 12, 168-180. [CrossRef] [PubMed]

5. Gama, B.E.; Lacerda, M.V.G.; Daniel-Ribeiro, C.T.; Ferreira-da-Cruz, M.F.F. Chemoresistance of Plasmodium falciparum and Plasmodium vivax parasites in Brazil: Consequences on disease morbidity and control. Mem. Inst. Oswaldo Cruz. 2011, 106, 159-166. [CrossRef] [PubMed]

6. Haynes, J.D.; Diggs, C.L.; Hines, F.A.; Desjardins, R.E. Culture of human malaria parasites Plasmodium falciparum. Nature 1976, 263, 767-769. [CrossRef] [PubMed]

7. White, N.J. Antimalarial drug resistance. J. Clin. Investig. 2004, 113, 1084-1092. [CrossRef] [PubMed]

8. Widyawaruyanti, A.; Devi, A.P.; Fatria1, N.; Tumewu, L.; Tantular, I.S.; Hafid, A.F. In vitro antimalarial activity screening of several Indonesian plants using hrp2 assay. Int. J. Pharm. Pharm. Sci. 2014, 6, 125-128.

9. Wells, C.D.; Cegielski, J.P.; Nelson, L.J.; Laserson, K.F.; Holtz, T.H.; Finlay, A.; Castro, K.G.; Weyer, K. HIV infection and multidrug-resistant tuberculosis-the perfect storm. J. Infect. Dis. 2007, 196, S68-S107. [CrossRef] [PubMed]

10. Khan, M.W.; Alam, M.J.; Rashid, M.A.; Chowdhury, R. A new structural alternative in benzo[b]furans for antimicrobial activity. Bioorg. Med. Chem. 2005, 13, 4796-4805. [CrossRef] [PubMed]

11. Abdel-Wahab, B.F.; Khidre, R.E.; Farahat, A.A.; El-Ahl, A.A.S. 2-Chloroquinoline-3-carbaldehydes: Synthesis, reactions and applications. Arkivoc 2012, I, 211-276. [CrossRef]

12. Dominguez, J.; Basante, W.; Charris, J.; Riggione, F. Synthesis and activity of some quinolone derivatives against Plasmodium falciparum in vitro. Fermaco 1996, 51, 407-412.

13. Ali, M.M.; Rajanna, K.C.; Prakash, P.K.S. An Efficient and Facile Synthesis of 2-Chloro-3-formyl Quinolines from Acetanilides in Micellar Media by Vilsmeier-Haack Cyclisation. Synlett 2001, 2, 251-253.

14. Pokalwar, R.U.; Hangarge, R.V.; Maske, P.V.; Shingare, M.S. Synthesis and antibacterial activities of $\alpha$-hydroxyphosphonates and $\alpha$-acetyloxyphosphonates derived from 2-chloroquinoline-3-carbaldehyde. Arkivoc 2006, 11, 196-204.

15. Khidre, R.E.; Abu-Hashem, A.A.; El-Shazly, M. Synthesis and anti-microbial activity of some 1-substituted amino-4,6-dimethyl-2-oxo-pyridine-3-carbonitrile derivatives. Eur. J. Med. Chem. 2011, 46, 5057-5064. [CrossRef] [PubMed]

16. Kaur, K.; Jain, M.; Reddy, R.P.; Jain, R. Quinolines and structurally related heterocycles as antimalarials. Eur. J. Med. Chem. 2010, 45, 3245-3264. [CrossRef] [PubMed]

17. Abdou, W.M.; Kamel, A.A.; Khidre, R.E.; Geronikaki, A.; Ekonomopoulou, M.T. Synthesis of 5- and 6-N-heterocyclic methylenebisphosphonate derivatives of cytogenetic activity in normal human lymphocyte cultures. Chem. Biol. Drug. Des. 2012, 79, 719-730. [CrossRef] [PubMed]

18. Abdou, W.M.; Shaddy, A.A.; Khidre, R.E.; Awad, G.E.A. Synthesis and Antimicrobial Evaluation of Newly Synthesized N, S-Bisphosphonate Derivatives. J. Heterocycl. Chem. 2015. [CrossRef]

19. Tayebee, R.; Amini, M.M.; Ghadamgahi, M.; Armaghan, $\mathrm{M}_{1} \mathrm{H}_{5} \mathrm{PW}_{10} \mathrm{~V}_{2} \mathrm{O}_{40}$ /Pip-SBA-15: A novel reusable organic-inorganic hybrid material as potent Lewis acid catalyst for one-pot solvent-free synthesis of 3,4-dihydropyrimidinones. J. Mol. Catal. Chem. 2013, 366, 266-274.

20. Biginelli, P. Aldehyde-urea derivatives of aceto-and oxaloacetic acids. Gazz. Chim. Ital. 1893, 23, 360-369.

21. Hu, E.H.; Sidler, D.R.; Dolling, U.-H. Unprecedented catalytic three component one-pot condensation reaction: An efficient synthesis of 5-alkoxycarbonyl-4-aryl-3,4-dihydropyrimidin-2(1H)-ones. J. Org. Chem. 1998, 63, 3454-3457. [CrossRef] 
22. Abdou, W.M.; Khidre, R.E.; Kamel, A.A. Elaborating on Efficient Anti-Proliferation Agents of Cancer Cells and Anti-Inflammatory-Based N-Bisphosphonic Acids. Arch. Pharm. Chem. Life Sci. 2012, 345, 123-136. [CrossRef] [PubMed]

23. Meth-Cohn, O.; Narine, B.; Tarnowski, B. A versatile new synthesis of quinolines and related fused pyridines, Part 5. The synthesis of 2-chloroquinoline-3-carbaldehydes. J. Chem. Soc. Perkin Trans. 1 1981, 9, 1520-1530.

24. Liu, Z.C.; Wang, B.D.; Li, B.; Wang, Q.; Yang, Z.Y.; Li, T.R.; Li, Y. Crystal structures, DNA-binding and cytotoxic activities studies of $\mathrm{Cu}(\mathrm{II})$ complexes with 2-oxo-quinoline-3-carbaldehyde Schiff-bases. Eur. J. Med. Chem. 2010, 45, 5353-5361. [CrossRef] [PubMed]

25. Kaur, B.; Kaur, R. Synthesis of fused quinazolinethiones and their S-alkyl/aryl derivatives. Arkivoc 2007, 15, 315-323.

26. Abelman, M.M.; Smith, S.C.; James, D.R. Cyclic ketones and substituted $\alpha$-keto acids as alternative substrates for novel Biginelli-like scaffold syntheses. Tetrahedron Lett. 2003, 44, 4559-4562. [CrossRef]

27. Obaid, A.; Sandhya, B.; Suresh, K.; Rajiv, K.; Md Quamrul, H. Design, Synthesis Chalcones/Amines and Evaluation of Novel 2-piperidinyl Quinoline as Potential Antidepressant Agents Lett. Drug Des. Discov. 2013, 10, 75-85.

28. Rao, K.R.; Bhanumathi, N.; Sattur, P.B. Synthesis of novel quino[2,3-b][1,5]benzodiazepin-12-ones. J. Heterocycl. Chem. 1991, 28, 1339-1340. [CrossRef]

29. Silva, L.F.R.; Montoia, A.; Amorim, R.C.N.; Melo, M.R.; Henrique, M.C.; Nunomura, S.M.; Costa, M.R.F.; Andrade Neto, V.F.; Costa, D.S.; Dantas, G.; et al. Comparative in vitro and in vivo antimalarial activity of the indole alkaloids ellipticine, olivacine, cryptolepine and a synthetic cryptolepine analog. Phytomedicine 2012, 20, 71-76. [CrossRef] [PubMed]

30. Lentner, C.; Lentner, C.; Wink, A. Student's t-distribution tables. In Geigy Scientific Tables Vol. 2. International Medical and Pharmaceutical Information; Ciba-Geigy Limited: Basel, Switzerland, 1982.

31. Finney, D.J. Probit Analysis, 3rd ed.; Cambridge University Press: Cambridge, UK, 1971.

Sample Availability: Samples of the compounds 4, 7, 8, and 12 are available from the authors.

(C) 2016 by the authors; licensee MDPI, Basel, Switzerland. This article is an open access article distributed under the terms and conditions of the Creative Commons Attribution (CC-BY) license (http://creativecommons.org/licenses/by/4.0/). 